\title{
Phenobarbital overdose in an eleven-year-old-girl with attempted suicide
}

\author{
V Lily Limantara, MD; Made Widia, MD; Ketut Suwitra, MD; Endah Ardjana, MD
}

$\mathrm{P}$ henobarbital, a long-acting barbiturate, is often used in the treatment of epilepsy. Its toxic levels can profoundly suppress the central nervous system and potentially result in death or respiratory failure. Consequently, deliberate overdose of phenobarbital constitutes a medical emergency. ${ }^{1}$

The incidence of phenobarbital overdose has declined in the past decade. In United States, during the 1970's, it was used commonly in suicidal attempts. Over the last several years, mortality rates from barbiturate poisoning declined markedly from $10 \%$ in the 1970 's to $1 \%$ in the 1990 's. This is thought to be due largely to improved supportive and therapeutic regimens. ${ }^{1}$

Along with supportive care, patient management of phenobarbital overdose involves reduction in absorption and enhancement in elimination. ${ }^{2}$ Gastrointestinal absorption is reduced by cathartics and activated charcoal, whereas establishment of an alkaline diuresis will enhance elimination. Although most patients are manageable with alkaline diuresis, hemodialysis or hemoperfusion may be used in critically ill overdosed patients. Since the degree of protein binding is high, hemoperfusion is generally considered more effective than hemodialysis in eliminating phenobarbital. ${ }^{3,4}$ Management of drug overdose associated with attempted suicide must be comprehensive and include psychiatric and psychological approach. ${ }^{5}$

This report describes a patient with life-threatening phenobarbital overdose, treated successfully with hemodialysis, using a high-flux, high-efficiency dialyzer and high blood flow rates. The rapid fall in phenobarbital levels and the dramatic clinical response noted during the procedure supports this technique as an effective therapy in such patients.

\section{Case Report}

An eleven-year-old girl, was brought to the emergency room at Sanglah Hospital on December 3, 2002 at 08:00 am after being found unconscious. A family member stated that the patient was depressed and had problems with her mother the night before. The following morning, the patient became less responsive and could not be awakened, and an empty bottle of her epileptic drug was found in her room. According to her father, the bottle contained 25 pills of phenobarbital $100 \mathrm{mg}$. She was initially diagnosed with epilepsy on November 1999

Presented at The $2^{\text {nd }}$ Annual IDAI Scientific Meeting, Batam, Indonesia, 12-14 Juli 2004

From the Department of Child Health (VLL, MW, EA) and Internal Medicine (KS), Medical School, Udayana University, Sanglah Hospital, Denpasar, Indonesia.

Reprint requests to: V Lily Limantara, MD, Department of Child Health, Medical School, Udayana University, Sanglah Hospital, Jalan Nias, Denpasar, Bali, Indonesia. Tel. 62-361-227911/227915, Ext. 128; Fax. 62-361-244038. 
and was treated with phenobarbital $100 \mathrm{mg}$ once daily and phenytoin $50 \mathrm{mg}$ twice daily ever since then. There was history of suicidal behavior in this patient, no history of parental depression in the family. She was first brought to Wangaya hospital at 02:00 am and then referred to Sanglah Hospital.

The patient was comatose with a Glasgow Coma Score of E1V1M1. Her pulse rate was 140 beats/minute, respiration rate was 32 breaths/minute, blood pressure was $90 / 50 \mathrm{mmHg}$, axillary temperature was $37.6^{\circ} \mathrm{C}$, body height was $139 \mathrm{~cm}$, and body weight was $40 \mathrm{~kg}$ (well nourished). On physical examination, we found that the pupils were isocore and had a diameter of $3 \mathrm{~mm}$, and light reflexes were positive. Neck mobility was normal. Ear, nose, and throat examination revealed normal. Breath and heart sounds were normal. Liver and spleen were not palpable and bowel sounds were normal. Extremities were warm and without cyanosis. Pathological and deep tendon reflexes were absent. Laboratory examination on admission revealed WBC was 4.7 K/uL, hemoglobin was $15.5 \mathrm{~g} / \mathrm{dL}$, hematocrite was $45.8 \%$, and platelet count was $226 \mathrm{~K} / \mathrm{uL}$. Serum examination revealed blood sugar was $113 \mathrm{mg} /$ $\mathrm{dL}$, BUN $5 \mathrm{mg} / \mathrm{dL}$, and creatinin serum was $0.6 \mathrm{mg} /$ dL. Serum transaminases were within normal limit. Blood gas analysis revealed $\mathrm{pH}$ 7.372, $\mathrm{pCO}_{2} 42.6$ $\mathrm{mmHg}, \mathrm{pO}_{2} 70.2 \mathrm{mmHg}$, and $\mathrm{HCO}_{3} 28 \mathrm{mmol} / \mathrm{L}$. Serum electrolyte revealed sodium $128 \mathrm{mmol} / \mathrm{L}$ and potassium $4.0 \mathrm{mmol} / \mathrm{L}$. Urinalysis examination was within normal limit.

The patient was diagnosed as suspected phenobarbital overdose due to attempted suicide, and serum phenobarbital level was examined. The patient was treated with supportive therapy and was consulted to the Nephrology Division, Department of Internal Medicine for hemodialysis. The nephrologists suggested conducting a forced alkaline diuresis while monitoring the level of consciousness, serum electrolyte, and sign of fluid overload.

An alkaline forced diuresis was performed using sodium bicarbonate of $1 \mathrm{mEq} / \mathrm{kgBW} /$ day $(\sim 40$ $\mathrm{mEq} / \mathrm{d}$ ) added to a Dextrose $5 \%$ infusion, and furosemide $1 \mathrm{mg} / \mathrm{kgBW}$ every 6 hours $(\sim 160 \mathrm{mg} / \mathrm{d})$ added to a $\mathrm{NaCl} 0.9 \%$ solution. Total intravenous fluid administration was calculated to maintain a urine output of $2 \mathrm{~mL} / \mathrm{kg} / \mathrm{h}(\sim 2000 \mathrm{~mL} / \mathrm{d})$.
A phenobarbital level obtained 5 hours after admission was $129.06 \mathrm{mg} / \mathrm{mL}$. On the following day, after 24 hours of forced alkaline diuresis, the patient was still comatose. This was due to the extremely high blood level of phenobarbital. There was also no response to the forced diuresis, the patient was subsequently initiated on hemodialysis, approximately 33 hours after hospital admission.

The patient was dialyzed for 3 hours with a femoral catheter. High-flux, high-efficiency, hollow fibers were used in the procedure. The blood flow rate was $200 \mathrm{~mL} / \mathrm{min}$, and the dialysate flow rate was $500 \mathrm{~mL} / \mathrm{min}$. By approximately 2 hours of the procedure, the patient began to show spontaneous movement and was able to say her name and also asked for a meal. Her mental status continued to improve, and by the end of the treatment, she was able to respond appropriately to verbal commands. Her clinical condition remained stable, with no subsequent deterioration after discontinuation of dialysis. Blood gas analysis and serum electrolyte examination were normal. Phenobarbital level obtained one day after hemodialysis was $24.62 \mathrm{mg} / \mathrm{mL}$.

On December 7, 2002, three days after hemodialysis, the patient was discharged from the hospital in good condition and was consulted to the Outpatient Clinic at the Psychiatry and Psychology Department. Results from the psychiatrist revealed adolescent depression with suicidal attempts and from the psychologist revealed that the patient was of normal intelligence (IQ 104) and had an extrovert personality. The patient was given moclobemide for 6 months in treatment of depression. Individual and family counseling was also provided for her and her parents. Follow-up study was carried on an outpatient basis.

\section{Discussion}

Phenobarbital is a long acting barbiturate, with a structural formula 5-phenyl-5-ethylbabituric acid, ${ }^{6}$ and like all barbiturates suppress the activity of excitable tissue, including the CNS, the peripheral nervous system, and the cardiovascular system. It also depresses gastrointestinal function and has a number of effects on hepatic function. Effect on the respiratory system is due mainly to CNS inhibition. ${ }^{1}$ 
In massive overdose, patients present coma accompanied by cardio-respiratory collapse. All effort should be made to identify the ingested substance and the circumstances of ingestion including searching for corroborating evidence (e.g. empty bottles, pill count, and a suicide note), questioning family for patient 's chronic medical conditions, prior attempts of suicide, alcohol and drug use, and allergies. ${ }^{5}$

Clinically, CNS depression occurs in a graded fashion, progressing from sedation, anesthesia, coma, and death due to respiratory arrest. Respiratory depression also occurs in graded, dose-dependent fashion starting with mild inhibition of the neurogenic respiratory drive and progressing to loss of hypoxic drive. Barbiturates depress the vasomotor centers of the medulla, resulting in arteriolar and venous dilatation and hypotension, progressing to shock. It also depresses the sympathetic ganglia, cardiac contractility, and smooth muscle and vascular tone, resulting in bradycardia, cardiovascular collapse, and shock. In the gastrointestinal system, it reduces muscle tone and peristaltic function, resulting in gastric dilatation with delayed gastric emptying as well as ileus and bowel distention. ${ }^{1,6}$

The grading of phenobarbital poisoning was based on Matthew's EEG findings (Table 1) or Reed's classification of coma (Table 2)., ${ }^{1,2}$ In our case, according to Reed's classification of coma, the patient was in grade III.

Oral absorption of phenobarbital is complete but somewhat slow; peak concentrations in plasma occur several hours after a single dose, $40 \%$ to $60 \%$ is bound to plasma proteins and to a similar extent in tissues, including brain. Half-life of phenobarbital ranges from $96-140$ hours. ${ }^{6}$ Phenobarbital is a weak acid, up to $25 \%$ is eliminated by $\mathrm{pH}$-dependent renal excretion of the unchanged drug, the remainder is inactivated by hepatic microsomal enzymes. Repeated administration shortens the half-life due to tolerance caused by induction of microsomal enzymes. $^{6}$

Phenobarbital plasma concentrations of 10 to $35 \mathrm{mg} / \mathrm{mL}$ are usually recommended for control of seizures. The relationship between plasma concentration and adverse effects varies in accordance with the development of tolerance. Concentrations greater than $60 \mathrm{mg} / \mathrm{mL}$ is associated with marked intoxication. ${ }^{6}$ Concentrations of $35-80 \mathrm{mg} / \mathrm{mL}$ will develop sluggishness, ataxia and nystagmus. Coma with reflexes will develop at a concentration of 65 $117 \mathrm{mg} / \mathrm{mL}$, and without reflexes at above $100 \mathrm{mg} /$ $\mathrm{mL}{ }^{7}$

In our case, phenobarbital level obtained 5 hours after admission was $129.06 \mathrm{mg} / \mathrm{mL}$ and the patient was in deep coma without reflexes. This finding confirmed the diagnosis of phenobarbital overdose. The absence of respiratory distress maybe due to tolerance developed from approximately 3 years of chronic administration.

Differential diagnosis is determined by the potential cause of depressed consciousness level. In addition to structural and medical causes of coma, toxicological causes must always be considered.

Table 1. Grading of phenobarbital polsoning according to Mathew's EEG

\begin{tabular}{ll}
\hline Grade I & alpha rhythm with beta waves and a few theta waves \\
Grade II & predominant theta waves with some alpha, beta, and delta waves \\
Grade III & predominant delta waves mixed with some theta waves \\
Grade IV & delta waves with occasional isoelectric intervals \\
Grade V & suppression alternating with burst activity of several seconds \\
Grade VI & suppression with occasional burst activity of $1 / 2$ second \\
Grade VII & isoelectric
\end{tabular}

Table 2. Grading of phenobarbital poisoning according to Reed's classification of coma

\begin{tabular}{ll}
\hline Grade 0 & asleep but arouses to spoken command \\
Grade I & comatose, withdraws to painful stimuli, vital signs and deep tendon reflexes (DTRs) normal \\
Grade II & comatose and unresponsive to painful stimuli, vital signs and DTRs normal \\
Grade II & comatose and unresponsive to painful stimuli, vital signs normal and DTRs absent \\
Grade IV & comatose and unresponsive to painful stimuli, with cardiovascular and respiratory collapse
\end{tabular}


Barbiturate overdose may present features of an opioid overdose, including pinpoint pupils, respiratory depression, and altered mental status. A barbiturate coma may also be extremely deep that a patient can lose all reflexes and encounter brain death. ${ }^{2,7}$

Currently, management strategies fall into three major areas: supportive care, decontamination, and enhancement of elimination. The basis of therapy is optimal supportive care, with treatment interventions aimed at specific problems as they develop. The most frequent problem encountered is coma with or without respiratory depression. The priority in management, therefore, must focus on providing adequate oxygenation, ventilation, and airway protection. . $^{1,8,9}$

Decontamination is commonly done using activated charcoal administered orally or by nasogastric tube. Often a cathartic, such as sorbitol or magnesium sulfate, is administered to prevent constipation and facilitates charcoal absorption more rapidly through the gastrointestinal tract, although the clinical efficacy of this treatment remains unproven. ${ }^{1,7}$ Multiple doses of activated charcoal have been shown to enhance the nonrenal clearance and also significantly reduce the serum half-life of phenobarbital. ${ }^{2}$

Another measure for decontamination is alkalinization of urine to a $\mathrm{pH}$ greater than 7.5 to 8.0. Manipulating urine $\mathrm{pH}$ in favor of the ionized form of the drug and allowing it to trap in the renal tubular space, results in increased excretion. ${ }^{2}$ Alkalinization can be accomplished with an initial sodium bicarbonate bolus of $1 \mathrm{mEq} / \mathrm{kg}$ followed by a constant infusion, accompanied with forced diuresis using furosemide. However, this technique has complications such as potential excess fluid or bicarbonate administration. ${ }^{\text {? }}$

Frenia et $\mathrm{al}^{10}$ in their study reported that both urinary alkalinization and multiple doses of activated charcoal are effective for the enhancement of phenobarbital elimination, yet multiple-dose charcoal was superior to urinary alkalinization.

In our case, we first gave supportive therapy of oxygen and intravenous fluid while maintaining airway protection. Afterwards, we initiated an alkaline forced diuresis after consulting a nephrologist. We did not perform decontamination with activated charcoal since the patient was in deep coma.
Hemodialysis or hemoperfusion is an extracorporeal alternative in eliminating drugs. However, drugs which are highly protein bound are not effectively removed by hemodialysis. On the contrary, hemoperfusion is effective in removing highly protein bound drugs, it allows circulating blood to come in direct contact with substances capable of absorbing toxins. ${ }^{3,4}$ Phenobarbital has a relatively small volume of distribution ( $0.5 \mathrm{~L} / \mathrm{kg}$ body weight), yet $40 \%$ to $60 \%$ is protein bound. ${ }^{2}$ The latter characteristic concludes hemoperfusion as the mode of preference for extracorporeal therapy in barbiturate poisoning. ${ }^{3,4}$

Chronic users of phenobarbital may tolerate very high levels with minimal symptoms. Therefore, a decision to dialyze a patient with phenobarbital overdose should be based on the evidence of severe toxicity unresponsive to conservative management, rather than on blood levels. ${ }^{7}$

In our case, after an alkaline forced diuresis was done for 24 hours, the patient was still comatose. A second consultation to the nephrologist resulted in the decision to perform hemodialysis on this patient. Approximately 33 hours after admission, the patient was dialyzed. Before hemodialysis, the blood phenobarbital level was $129.06 \mathrm{mg} / \mathrm{mL}$. One day after hemodialysis, the blood level had fallen to $24.62 \mathrm{mg} / \mathrm{mL}$. This case illustrates that hemodialysis can rapidly lower phenobarbital level in blood and supports the use of this procedure in patients with life-threatening phenobarbital overdose.

The effectiveness of the procedure, specifically in this case, can be attributed to the use of a highefficiency dialyzer and high blood flow rates. ${ }^{11} \mathrm{Al}$ though hemoperfusion is a generally recommended form of extra-corporeal therapy for phenobarbital overdose, this report suggests that hemodialysis is also a highly effective treatment for acute phenobarbital poisoning when employed in this manner, thus hemodialysis was preferred over hemoperfusion as the therapy implemented. While the same machine is used for both hemodialysis and hemoperfusion, hemoperfusion is not as readily available as hemodialysis. Cartridges are not available in many hospitals, and familiarity with hemoperfusion, even by nephrologists, is limited owing to its rare frequency of use. Certain complications occur frequently, in- 
cluding hypotension, thrombocytopenia, leukopenia, nonselective binding of important molecules, and electrolyte disturbances. ${ }^{3,4}$

Previous reports have described the effect of hemodialysis on phenobarbital poisoning. Palmer ${ }^{12}$ described a patient with phenobarbital poisoning treated with 4 hours of hemodialysis with a 1.5 $\mathrm{m}^{2}$ hollow fiber dialyzer and a blood flow rate of $400 \mathrm{~mL} / \mathrm{min}$. During the procedure, clearance values averaged $174 \mathrm{~mL} / \mathrm{min}$ and the $\mathrm{K}^{\mathrm{el}}$ (elimination rate) was 0.22 per hour. Half-life decreased to 3.2 hours as compared to 29 hours when treated with an alkaline forced diuresis. During the procedure, the phenobarbital level decreased from 130 to $53 \mathrm{mg} / \mathrm{mL}$.

In this case phenobarbital clearance was much higher than previously reported with hemodialysis. Given that phenobarbital is significantly protein bound, it was unexpected that hemodialysis even with the use of a high-efficiency dialyzer was found quite effective in removing the drug.

Complications in such a case may arise due to the drug overdose itself and therapy. These complications, in barbiturate poisoning, include acute respiratory distress syndrome (ARDS), pneumonia, aspiration pneumonitis, atelectasis, anoxic encephalopathy, cerebral edema, rhabdomyolysis and renal failure. Those of therapy are pulmonary and cerebral edema, fluid overload, hypernatremia, hypokalemia, hypomagnesemia, and hypocalcemia. ${ }^{1}$ In our case, none of the above complications occurred.

Prognoses of phenobarbital overdose during the last decades have been good. The hospital mortality is less than $2 \%$. The decrease in mortality is likely due to good supportive care and improved therapeutic regimens. ${ }^{1}$

Once acute effect and secondary complications have resolved, psychiatric assessment is required. Psychiatric management is important for patients with suicidal behavior associated with depression. ${ }^{2}$ Our patient was consulted to the psychiatry and psychology department in the outpatient clinic after discharge from hospital. The patient was given an antidepressant medication (moclobemide, MAOI) for 6 months, and also had individual and family counseling. This patient is still being monitored in the outpatient clinic.

\section{Conclusion}

A case of phenobarbital overdose has been reported. The definitive diagnosis was established by history, clinical examination, and phenobarbital level obtained after admission. Treatments include supportive therapy, a forced alkaline diuresis, and hemodialysis. The rapid fall in phenobarbital levels and the dramatic clinical response noted during the procedure support that this technique is an effective therapy in patients with life-threatening phenobarbital intoxication. The patient was discharged in good condition three days after hemodialysis. Complications of barbiturate overdose and of therapy for barbiturate poisoning did not occur in this patient. Follow up of the patient is still being carried out in outpatient clinic in order to manage psychological problems and prevent suicidal behavior. We do not suggest that all patients with phenobarbital overdose should be treated with hemodialysis, because in fact, most cases of phenobarbital overdose can be treated by less invasive methods.

\section{References}

1. Habal R. Toxicity, barbiturate. Available from: URL: http:/ /www.emedicine.com/med/by name/toxicity-barbiturate. htm

2. Homan CS, Ryan JG. Enhancement of elimination. In: Viccellio P, editor. Handbook of medical toxicology. 1st ed. Boston: Little, Brown and Company; 2000. p. 106-17.

3. Winchester JF, Kitiyakara C. Use of dialysis and hemoperfusion in treatment of poisoning. In: Daugirdas JT, Blake PG, Ing TS, editors. Handbook of dialysis. 3rd ed. Philadelphia: Lippincott Williams \& Wilkins; 2001. p. 263-80.

4. Levy J. Haemodialysis and haemoperfusion for poisoning. In: Levy J, Morgan J, Brown E, editors. Oxford handbook of dialysis. 1st ed. London: Oxford University Press; 2001. p. 204-7.

5. American Academy of Child and Adolescent Psychiatry. Practice parameter for the assessment and treatment of children and adolescents with suicidal behavior. J Am Acad Child Adolesc Psychiatry 2001;40(7):24-51.

6. McNamara JO. Drugs effective in therapy of the epilepsies. In: Hardman JG, Limbird LE, Gilman AG, editors. Goodman \& Gilman's the pharmacological basis of thera- 
peutics. 10th ed. New York: McGraw-Hill; 2001. p. $412-$ 9.

7. Schiebel N, Vicas I. Barbiturates. In: Delaney KA, Ling LJ, Erickson T, Ford MD, editors. Clinical toxicology. 1st ed. Philadelphia: WB Saunders; 2001. p. 569-73.

8. Abbruzzi G, Stork CM. Pediatric toxicologic concerns. Emerg Med Clin North Am 2002;20(1):223-47.

9. Lindberg $\mathrm{MC}$, Cunningham $\mathrm{A}$, Lindberg $\mathrm{NH}$. Acute phenobarbital intoxication. South Med J 1992;85(8):803-7.
10. Frenia ML, Schauben JL, Wears RL. Multiple-dose activated charcoal compared to urinary alkalinization for the enhancement of phenobarbital elimination. J Toxicol Clin Toxicol 1996;34(2):169-75.

11. Pastan S, Bailey J. Dialysis therapy. N Engl J Med 1998;338(20):1428-37.

12. Palmer BF. Effectiveness of hemodialysis in the extracorporeal therapy of phenobarbital overdose. Am J Kidney Dis 2000;36(3):640-3. 